\title{
A Pathfinder for Comic Books and Graphic Novels
}

$\mathrm{T}$ his pathfinder will assist patrons in a school library as they find resources and complete research about the growing world of comic books and graphic novels. Comic books and comic book-inspired entertainment are more popular than ever; comics are increasingly a part of English/ Language Arts curriculum; and library users are more and more often seeking graphic novels (and information about them) when they go to the library. This pathfinder collects sources which help address patrons' needs regarding this subject, providing the starting points for research about comics. Patrons using this pathfinder will be introduced to a variety of sources that allow them to become familiar with the creative forces behind and the imaginative creations within comic pages. The American Association of School Librarians (AASL) has standards 4.1.2 (Read widely and fluently to make connections with self, the world, and previous reading) and 4.1.3 (Respond to literature and creative expressions of ideas in various formats and genres), and this pathfinder, for reference materials for a specific and sometimes-overlooked genre of literature, helps meet both of these standards. The Common Core Standards for English/Language Arts \& Literacy address several elements for texts which apply to comic books and graphic novels. For example, the high school standards for Reading: Literature include 9-10.2 \& 10-11.2 (Determine theme or central idea of a text and analyze in details its development over the course of the text, including how it emerges and is shaped and refined by specific details), 9.10-3 (Analyze how complex characters develop over the course of a text, interact with other characters, and advance the plot or develop the theme), 9-10.9 (Analyze how an author draws on and transforms source material in a specific work), 11-12.3 (Analyze the impact of the author's choices regarding how to develop and relate elements of a story), and 11-12.7 (Analyze multiple interpretations of a story, drama, or poem, evaluating how each version interprets the source text). The majority of materials provided to ELA teachers focuses on traditional printed texts, but the movement in education is to use a variety of sources and textual types, with graphic novels at the forefront of this movement. This pathfinder helps both teachers and students in a school library find appropriate and effective resources.

\section{Introduction}

Alternative media are becoming more widely accepted as forms of literature. Comic books and graphic novels are now mainstream, with characters and storylines appearing in movies, cartoons, video games, television shows, and more. Comics and graphic novels are a billion dollar industry that can often go overlooked in the minds of readers. The resources in this pathfinder will open readers' eyes to the universe of stories and characters that are contained in comic books. It will also give readers an idea of the rich history of the industry and the powerful impact that comic books and graphic novels have had on popular culture. In addition, it will provide teachers with a multitude of literary resources that they may otherwise overlook.

\section{Classification Numbers}

Examples of Library of Congress Classification numbers to browse:

- PN6725.S56 2003

- PN6725.W58 1989

- PN6707.C65 1993

Examples of Dewey Decimal Classification numbers to browse:

- 741 (comic books). Materials about film and television adaptations of comics and videography lists of films based on comic book properties can also be found with 741, but further DDC numbers to browse are 777 (cinematography and videography) and 791 (film adaptations).

\section{Subject Headings and Keywords}

Keywords to be used in searches include:

\begin{tabular}{|l|l|l|}
\hline comic books & visual storytelling & Archie \\
\hline graphic novels & Stan Lee & Golden age \\
\hline superheros & X-Men & Silver age \\
\hline Marvel & Superman & Image comics \\
\hline DC & superhero movies & comic adaptations \\
\hline sequential art & & \\
\hline
\end{tabular}




\section{Library of Congress Subject Headings}

\begin{tabular}{|l|l|}
\hline Class P & Language and Literature \\
\hline Subclass PN & Literature (General) \\
\hline PN6700 - PN6790 & Comic books, strips, etc. \\
\hline Class Z & Bibliography, Library Science, Information Resources (General) \\
\hline Z691 - Z692 & Special classes of materials \\
\hline Z692.G7 & Graphic Novels \\
\hline Class N & Fine Arts \\
\hline Subclass NC & Drawing, Design, Illustration \\
\hline NC1300 - NC1766 & Pictorial humor, caricature, etc. \\
\hline NC1764 - NC1764.8 & Comic books, strips, etc. \\
\hline Use for 2013 operations & $\$ 16,000.00$ \\
\hline NC1764.8 x2 & X-men (fictitious characters) \\
\hline
\end{tabular}

\section{Reference Sources}

\section{Bibliographies}

Barrier, M., and Williams, M. (Eds.). (1981). A Smithsonian book of comic-book comics. New York, NY: Smithsonian Institution Press \& Harry N. Abrams.

A companion volume to the Smithsonian Collection of Newspaper Comics, this anthology is divided into twelve sections, with historical background and bibliographic information for each subject (a noteworthy character, creation, or both from the early history of comics), followed by a reprint of a classic story or stories representing that section. This volume provides a valuable overview and resource for the Golden Age of comics, with information and stories from 1938 (and the premiere of Superman) through 1955 (and the peak of EC Horror comics). Readers can use this resource as an introduction to the classic days of early comic books.

Gravett, P. (Ed.). (2011). 1001 comics you must read before you die: The ultimate guide to comic books, graphic novels and manga. New York, NY: Universe.

The history of comics is long and varied, and this tome seeks to recommend a path of highlights through that history. Starting with examples of comic art from the nineteenth century (with the earliest sample from 1837), this book progresses from the Victorian era through the digital age with synopses, explanations, and bibliographic information on just over a thousand significant titles. The highlights include comic strips, but its focus is primarily on comic books (including single titles, story arcs over several issues, bound collections, and long-form texts written as single bound narratives). Over half of these spotlighted titles were printed since 1990, giving the reader an impressive introduction to more recent titles in the history of these books.

Gifford, D. (1984). The International book of comics. New York, NY: Crescent Books.

For the casual reader, comic books belong to the United States, with DC \& Marvel Comics dominating the domestic marketplace. However, comics are part of a global publishing industry, and this encyclopedia is an excellent introduction to graphic literature produced around the world. The entries are collected thematically (such as comics inspired by western heroes in film, or holidaybased comics, or "Superheroes at War"), with short essays providing historical and bibliographical overviews alongside a myriad of illustrations. Though this reference is now somewhat dated, it remains a solid introduction to the international world of comics.

Howard, S., and Jackson, R. (2013). Black comics: Politics of race and representation. New York, NY: Bloomsbury.

This reference is an overview of black comics, looking at both the presentation of characters of color in comic books and comic strips, and considering the history of African-American creators in the comics industry. Given the book's examination of this broad topic, it includes sections on comic strips and political cartoons, but it does also include discussions of the presence of black characters (with particular emphasis on superheroes and superheroines) in comic books. The volume sheds considerable light on the topic, which has not received as much discussion in the general overviews of comic books available. 
Lent, J. (2003). Comic art of Europe through 2000: An international bibliography. Westport, CT: Praeger.

A two-volume bibliographic record, this reference set provides its readers with a comprehensive means of finding articles written about the comics industry throughout Europe (including the British Isles). The bibliography is broken into large sections ("Global and Comparative Perspectives" and "Continental, Regional, Comparative Perspectives," as well as a series of country perspectives, dividing the reference based on the geographical subject of each article). Within each comparative section, entries are broken into a series of subsection headings: references; artistic aspects; cartooning, cartoons; cartoonists and their works; characters and titles; communication aspects; comparative aspects; conscientization aspects (looking at the beneficial use and potential of comics, such as in teaching readers about dangerous issues or in promoting causes); historical aspects; legal aspects; technical aspects; theoretical aspects; animation; caricature; comic books; comic strips; and political cartoons. These sub-headings are also found in the sections on countries with large comics industries, such as France, Great Britain, and Germany, but for those countries with smaller industries (and with fewer articles about those industries), the bibliographic entries are simply labelled under headings for the respective nations. The second volume includes an addendum of later-published works, broken down by nation. This work is an excellent starting point for readers interested in the discussion of comic books from Europe.

Lent, J. (2005). Comic art of the United States through 2000, animation and cartoons: An international bibliography. Westport, CT: Praeger.

This popular culture bibliography and index is an effective guide to the world of comics scholarship, with entries on articles and books written about comic art in many forms. The book breaks its overview into large sections, starting with one on Canada and its comic art output (broken into subsections on types of art and the media in which the art would appear), before settling into a reference about work in the United States, providing looks at Comic Art in general (which in turn breaks into sub-sections on sources $\&$ resources, the use of comic art in various media, including comic books, various locations, including schools, and as a subject of discussion in conjunction with other topics, such as war, sports, education, and political correctness), as well as the use of comic art in a variety of ways (such as for illustrations and magazine cartoons, in animation, as caricature, and for political purposes). Lent is thorough with his study, particularly in finding articles written about American comics in other countries.

Lent, J. (2006). Comic books and comic strips in the United States through 2005: An international bibliography. Santa Barbara, CA: Greenwood.

Lent's text is a bibliographic record for both comic books and comic strips, listing information on printed materials about the comics industry and its output. Like Lent's bibliography for comics of Europe (see separate entry), this volume is an invaluable resource about its subject; it narrows the focus of Lent's bibliography of comic art in the US (see separate entry) by focusing just on comic books and strips (though the two do have considerable overlap). The reference is broken into separate sections for comic books and comic sections, with each part broken into a series of subsections: General Sources; Resources; Anthologies, Collections, Reprints; Artistic Aspects; Business Aspects; Collecting; Content, Form; Criticism, Reviews; Cultural Aspects; Exhibitions, Festivals, Awards; Historical Aspects; Legal and Ethical Aspects; Media, Popular Culture Connections; Scholarship, Theory; Readership; \& Technical and Technological Aspects. An addendum keeps the book up-to-date with entries on late articles. This reference is a thorough collection of writings about comics, allowing readers to use the work as a way to find works written about comics.

Robbins, T. (1999). From girls to grrrlz: A history of $O$ comics from teens to zines. San Franscisco, CA: Chronicle Books.

Robbins' book is a short reference on the history of comics about female characters. This brief overview provides context for its specialized history and bibliography in the broader world of comics history, with Robbins noting developments in the industry that parallel those discussed in depth in the pages of this work. The world of "girl comics" is an oft-forgotten element of the broader examinations of comics, and this reference is a welcome effort to address the topic.

Weiner, R.G. (2008). Marvel graphic novels and related publications: An annotated guide to comics, prose novels, children's books, articles, criticism and reference works, 1965 - 2005. Jefferson, NC: McFarland \& Company. Retrieved from http://ebrary.com

This source contains bibliographic information, including author, artist, volume, publication date, ISBN information, and summary descriptions of each item contained, covering a forty-year span of Marvel comics. It 
contains information on Marvel history, its major and minor characters, special volumes, and related publications, as well as several scholarly works.

\section{Indexes and Abstracts}

Archie Universe. (2015). Retrieved from

http://www.mightycrusaders.net/

Though the modern comics landscape is primarily dominated by DC and Marvel Comics, the teen-friendly Archie Comics have just as long a history and have a lasting legacy on the popular culture front. This reference website provides several resources about the world of Riverdale depicted in the various Archie titles. The main page for this site, and the webpage's original focus, is the Mighty Crusaders, a superhero team created for Archie Publications during the Silver Age of comics, and several of the links are to pages about those titles and characters and their history. A casual comic book reader might not realize the extensive history of these characters, but this website rectifies that gap in knowledge, providing overviews of titles, bibliographic information on comics, biographical information on writers, reviews of unpublished work, overviews of toys and merchandise based on the superheroes, and recapping adaptations of the characters, including a thorough report on a shortlived old-time radio show based on one hero. However, the scope of the overall page is not limited just to the superheroic exploits published by Archie, as the site broadens to include reference material on the overall "Archie Universe," with the encyclopedia for Mighty Crusaders giving way to a fictional biography site of Who's Who in Archie Comics (with sub-sections for characters in the many titles published by Archie Publishing over the years) and a bibliographic overview from the history of the company. This site provides readers with a good introduction to the popular Archie series.

Thomas, R., and Schelly, B. (Eds.). (1997). Alter ego: The best of the legendary comics fanzine. Seattle, WA: Hamster Press.

The world of comic books has many facets, and one of the most significant (but often under-discussed) facets is the world of fandom. This collection highlights a category of "comics ephemera:" the fanzine. The anthology provides a collection of highlights from Alter Ego, one of the earliest fanzines (or fan-created magazines about the comics industry), with representative articles, art by both fans and industry professionals, trivia about comic books, creators, and characters, and examples of previously unpublished work and "lost" stories. This reference provides information on what would otherwise be lost material, as many fanzines have not been preserved (particularly given many were typed and photocopied, without any archives created for the issues).

Hamerlinck, P.C. (Ed.). (2001). Fawcett Companion: The Best of FCA. Raleigh, NC: TwoMorrows Publishing.

Like the overview of Alter Ego (see separate entry under Thomas \& Schelly), this reference book examines a fanzine, with this volume focusing on FCA (the fan-andcomics-historian-driven publication of the Fawcett Collectors of America), providing history, publication information, chronologies, galleries of covers, a publishers index, and information on the ongoing legacies for the publications of this publishing house (which only published comic books in the Golden Age of comics, from 1940-1953). A reader interested in Fawcett Comics would definitely be interested in this resource, as would scholars seeking examples of a particular fandom approach to comics or for information on the comics world beyond the more-often profiled Marvel \& DC Comics.

Irving, C. (2007). Blue Beetle companion: His many lives from 1939 to today. Raleigh, NC: TwoMorrows Publishing. The world of comic books is filled with significant figures, and Irving's book is an interesting example of a reference work on one of these characters. As the historical reference reveals, the superhero the Blue Beetle has had a long history (dating to the beginning of the Golden Age of comics and premiering just one year after Superman), including a variety of incarnations as well as being featured as a lead character by multiple publishers. This resource traces the history of the comic character through his many appearances in comic books, as well as detailing otherwise unknown, forgotten, or lost efforts to produce the character in comic strip and radio adaptations. The volume also includes bibliographic information on the character's appearances in different titles.

Beaty, B., and Weiner, S. (Eds.) (2012). Critical survey of graphic novels: Heroes \& superheroes. Ipswich, MA: Salem Press.

This two-volume reference set provides an overview, description, and analysis of over 130 graphic works in the superhero genre, starting with titles in the Bronze Age of comics (when the term "graphic novel" first began seeing wide use) through the modern era. The entries are alphabetical by the title of the work profiled, broken into clear sub-headings (for bibliographic information, plot, characters, artistic style, themes, and impact), and each 
entry has a "see also" line, pointing readers to further entries in this reference which relate and should be of interest. These volumes should prove valuable to both novice and experienced readers.

Beaty, B., and Weiner, S. (Eds.) (2013). Critical survey of graphic novels: History, theme, \& techniques. Ipswich, MA: Salem Press.

This volume of Beaty \& Weiner's overall series about comic books focuses on a variety of topics important to the understanding of graphic novels. With almost eighty essays about themes and concepts found in comics and about the relationship of comics to the greater world, this single-volume set is a one-stop reference for both history and legacy in sequential art. The essays are each broken into four sections: definition (a brief description of the time period or genre), introduction (offering a brief overview, making each entry accessible to all readers), the impact of the topic, and a bibliography for further reading. Of especial interest are the appendices, offering a glossary of terms and techniques, a bibliography about comics history, a guide to online resources, a timeline for comic books, major industry awards and their winners, and charts of recommended reading, providing ample opportunities for continued reading.

Beaty, B., and Weiner, S. (Eds.) (2012). Critical survey of graphic novels: Manga. Ipswich, MA: Salem Press.

This single-set volume from the Critical Survey of Graphic Novels series offers focus on the fast-growing and highlypopular Manga style of comics from Japan. Manga has taken a strong hold for many readers, and this resource examines almost seventy well-regarded works from the medium. Like Beaty \& Weiner's volumes on books from the superhero genre (see separate entry), each alphabetical entry in this reference includes bibliographic information, a publication history, an overview of the works' plot, characters, style, themes, and impact, and a listing for further reading on the topic.

Grand comics database. (2015). Retrieved from

www.comics.org

For immediate and ready information, the first source online about comic books is often the Grand Comics Database. This website is an online almanac, with data about comic publication and history, with the ability to get quick information about characters featured in comics, specific titles, and the personnel who have created these characters and titles over the years. The site is very userfriendly and has twenty search category options allowing for refinement of search terms. As an online database, the site is constantly being updated, and the one caveat a user needs to recall is that all information is provided by volunteers. However, the site has its contributors checking and double-checking each other, and much comic book history has been maintained and written by collectors and readers, so the reliance on volunteers is not unheard of. In the age of Web/Library 2.0, in fact, the use of a system in which dedicated volunteers input information is, in many ways, expected.

Image comics database. (2015). Retrieved from

http://imagecomics.wikia.com/wiki/Main_Page

This website contains thousands of entries about characters, titles, artists, writers, and history of Image Comics. Despite being a community-run wiki website, the Image database is extensive and should be a valuable asset to any library patron interested in the history of independent publishing or would like to learn more about the publishing house that has become the consistent third most popular publisher (thanks largely to the enormous popularity of titles like The Walking Dead) behind the DC and Marvel powerhouses.

Mike's amazing world of comics. (2015). Retrieved from http://www.dcindexes.com

Though it began as an online index for one avid collector's (nearly) exhaustive collection of comic books from one publisher (DC Comics, as evidenced in the URL), this website has grown to cover a plethora of publishers (the website offers nine "Amazing World of" sites for major publishers, but the database search allows the choice of fifty-three total publishers titles, with forty-eight imprints available within those publishers). The database feature allows a variety of searches for comic books, with a gallery providing cover images from the books and the story contents within each issue. One very popular feature for the site is "The Newsstand," which allows researchers to search what titles were published in a given month from 1933 to present (as of this writing, the information stops with December, 2014, but new data is added regularly, and, with the first quarter of 2015 now drawn to a close, that feature will likely update shortly to include the latest offerings). The site allows users to download information about comic books released by different publishers throughout those company's history and even features podcasts with discussions about comics and comic book history. Though it still maintains an entire category of "DC Features" on that publisher, there are also a few fun "side" features, such as a gallery of advertisements from 
comics for Saturday morning cartoons and of a specific series for Hostess desserts (featuring superhero characters). The scope and range of this site is impressive, and the information is very easy to access; the site is easily navigable for a user.

\section{Encyclopedias}

Booker, M.K. (Ed.). (2014). Comics through time: A history of icons, idols, and ideas. Santa Barbara, CA: Greenwood.

A four-volume history of comic strips and comic books, this series is a thorough encyclopedia of significant topics for the comics medium, including creators, major titles, publishers, and famous characters. Each entry provides a history of its subject, along with a "See Also" line of related entries, and a short bibliography for further reading. This reference set focuses primarily on American comics, but it does include international contributors to the industry. The expansive history provides quality entries which are both helpful as introductions to topics and for more in-depth study of each subject.

Booker, M.K. (2010). Encyclopedia of comic books and graphic novels. Santa Barbara, CA: Greenwood Press.

Many encyclopedias about comics have been produced, particularly with the growth of comics scholarship and with the success of comics-related adaptations in recent years. Booker's two-volume encyclopedia is one of the most thorough available. It also is one of the most upto-date. Its breadth and depth of coverage has caused it to supplant Maurice Horn's World Encyclopedia of Comics (1976, revised 1999) as the most thorough and effective reference for research, and it is particularly helpful in providing overviews and introductions to important writers, artists, and titles in comics history. Most entries offer recommended resources in selected bibliographies, and the encyclopedia offers a list of recommended sources about comic books in general (though it is subjective to suggest the "best" resources as it does). Though the book does skew to American comic book history, it does include entries on international publications.

DC comics encyclopedia: The definitive guide to the characters of the DC universe. (2004). New York, NY: DK Publishing. An encyclopedia of fictional characters, this large volume provides entries for over one thousand characters who have been featured in the pages of the books published by DC Comics. Each alphabetical entry provides for the character: an illustration, his/her first appearance (including the date of that publication), status (such as hero or villain), real name (if applicable), occupation, base of operations, height, weight, eye \& hair color, and any special powers/abilities. Each entry includes a history of the character. Besides being found in alphabetical order, the characters are also listed in a thorough index. Throughout the book, there are a series of two-page spreads providing short essays on key elements: Amazing Vehicles, Amazing Weapons, Amazing Bases, Alien Races, Great Team-Ups, Romantic Moments, Great Battles, and Strange Times and Places. For a reader interested in DC Comics, this book is a wealth of information.

\section{MarvelDirectory. (2014).}

Retrieved from marveldirectory.com

This website is a repository for all things related to Marvel Comics publications. The site is primarily an online encyclopedia, with tabs providing entries for individual characters, groups and teams, alien races, locations (both fictional creations and non-fictional uses of real places within a fictional context), other dimensions (the use of alternative worlds within the fiction of Marvel Comics), strength levels (as established within stories), miscellaneous (a potpourri of items which do not fit into other tabs, such as headquarters and vehicles for teams, the lost continent of Atlantis, armor for the superhero Iron Man, etc.), and a glossary (with brief definitions taken from the Official Handbook to the Marvel Universe, a limited issue comic series published in the 1980s), downloads of images and game codes for video games related to Marvel Comics. There are also tabs, with the pages stating "coming soon" for information on the Movie-Verse of Marvel Comics adaptations and for a store selling items related to the information in the directory. Within these tabs, there are other pages which simply state "Coming Soon," as the website is very much a work in progress; the links found in the locations section (which starts with a hyper-linked world map) are currently more likely to be under construction than ready. Despite some limitations, including the fact there is not an easy-to-use search box requireing site users to know exactly which category their search item might fall under or have the luck to choose the right spot), this website is a very interesting resource with considerable information available. The site is primarily an encyclopedia but also has aspects of a dictionary and an atlas, making it a sort of "one-stop shop" for Marvel Comics reference materials.

Marvel encyclopedia: The definitive guide to the characters of the Marvel universe. (2006). New York, NY: DK Publishing. Like the DC Comics Encyclopedia (see above), this onevolume encyclopedia gives detailed entries for fictional 
characters in the Marvel Universe. Each alphabetical entry for the characters provides an illustration and a short history, along with entries of key data on the figure (Real Name, if applicable, Occupation, Base, Height, Weight, Eyes, Hair, First Appearance, and Power). This volume features both alphabetical order for all character entries and a complete index. Interspersed throughout the book are two-page spreads detailing the publisher's history in each decade from the 1960s through the 2000s, respectively. This reference is an important volume for any reader looking for information on Marvel Comics.

Rovin, J. (1985). The encyclopedia of superheroes. New York, NY: Facts on File.

The scope of this encyclopedia is much broader than just comic books, but Rovin's work has a heavy emphasis on graphic creations. The book is an encyclopedia of over 1,300 characters (from comic books \& strips but also throughout literature, TV, film, and video games), with each alphabetic entry giving the character's name, appearances (noting the media in which the hero has been seen), alter ego (if applicable), first appearance, occupation, costume, tools and weapons (if applicable), and character biography, along with a characteristic quotation and a short comment section (often including a history of further appearances). The book features an impressive assemblage of characters, including appendices detailing information on superhero teams, "obscure or borderline" superheroes from the Golden Age of comics, foreign superheroes, minor superheroes (those who have appeared only once or in subordinate roles, including characters used in parodies and advertisements), and characters featured in the series Dial 'H' for Hero (a comic in which its protagonists become new and different superheroes with each issue). The reference work's introduction includes an interesting discussion of the concept of the superhero (and how the book chose to define characters for their inclusion in the encyclopedia), tracing the idea from ancient civilizations through modern comic books.

Rovin, J. (1987). The encyclopedia of supervillains. New York, NY: Facts on File.

A companion volume to The encyclopedia of superheroes, this sequel reference is an examination of the superpowered counterparts to the first book's heroic leads. Like that volume, each alphabetic entry gives the character's name, media in which he/she appears, real name, first appearance, costume description, weapons and chief henchmen (if applicable), character biography, a characteristic quotation (when available), and a short comment about the character's ongoing appearances and legacy. The entries for this work tend to be shorter than in the heroic book, allowing more villains to be profiled. The scope of this work covers many media, but the majority of entries come from the annals of comics. This work contains one appendix, detailing super-villain teams. Rovin also begins this collection with a thoughtful introductory essay about the nature of the super-villain in culture.

Rovin, J. (1994). Adventure heroes: Legendary characters from Odysseus to James Bond. New York, NY: Facts on File. The third volume by Rovin (see two previous entries), this encyclopedia covers the broadest territory, as adventure heroes are found in far more works and permutations than characters defined by superpowers. As with the other volumes, each alphabetic entry identifies the media in which the character has appeared, that character's first appearance, a fictional biography, and a short commentary (normally detailing the production and/or publication history for the figure). The reference work actually profiles fewer characters (the book boasts it has entries for more than 500) than either of the other volumes, but it does cover more far-reaching types of stories, having expanded its scope to include opera, folklore, and stage plays. Readers interested in the intersection of comics and other forms will find this an interesting encyclopedia. Perhaps one of its odder features, however, is its choice to alphabetize by first name, so that James Bond is under "J" and William Tell under "W," rather than "B" and "T," respectively; however, once readers realize this method the use of the text is simple. Once again, the introductory essay is an interesting overview of the topic.

\section{Dictionaries}

Cowsill, A. (2015). Marvel the Avengers: The ultimate character guide. New York, NY: DK Publishing.

This is an illustrated "biographical dictionary" of sorts that contains information on over 200 Marvel characters. Each character is given a short 100- to 200-word biography, as well as listing physical statistics and a 7-point ranking system for each character's attributes. The information breakdown is similar in brevity and content to a baseball card.

Don Markstein's Toonopedia. (2015). Retrieved from http://www.toonopedia.com/

This site is a sort of "biographical dictionary" for fictional characters. Toonopedia contains information for not just comic book and graphic novel characters, but 
also comic strip and cartoon characters. This website serves users who are curious as to the fictional "biography" of characters as well as background information of each character's creation. The website also lists the character's first appearance, publisher, medium (comic book, comic strip, cartoon series), and creator. Unfortunately, the website has not been updated in a few years, so new information about characters and information about new characters have not been provided. However, since this website focuses on the history of characters and their creation, the information is still very valuable.

\section{Ready-Reference}

Anchors, W. (Ed.). (1995). The superhero illustrated guidebook: A review of classic superhero television series. Dunlap, TN: Alpha Control Press.

A collection of episode guides for fantastic television series, this book collects material originally printed in Epi-Log, a fan-driven publication of episode guides and histories of science-fiction and fantasy series. This volume focuses on television series featuring super heroes, providing information on programs which adapt comic books to television and of series created for television (with several of these programs then adapted as comic books). Each guide features a synopsis of each episode, along with filmographic credits for each installment. Some of the series are also detailed in short essays about their production and history. Of particular interest to comic book readers are the essays provided alongside the episode guide for the original TV series The Flash, which detail the history of transferring the character from the comic book page to the small screen and which review the rogues gallery for the show, giving particular attention to how these villains relate to their comic book counterparts; the episode guide concludes with a discussion of an un-filmed script for the series. This reference work is a thorough example of studying the super hero in another medium.

Rogers, T. (1992). The super-hero photo guidebook. New York, NY: Image Publishing.

Rogers' visual guide to a myriad of television and film productions featuring super-hero characters offers over 150 images of these fantastic characters, along with brief filmographic information on the productions, along with a short explanation of the powers (if any) exhibited by the characters. Because the topic for this reference is super heroes, it is not limited solely to comic book adaptations, but the majority of the characters depicted have their roots in graphic fiction, and this volume is a good, though dated, resource.
Campbell, T. (2006). A history of webcomics v 1.0 - "the golden age": 1993-2005. San Antonio, TX: Antarctic Press. As the Internet has grown, so too has its influence on graphic novels. This reference, which takes a tongue-incheek approach to its subject, details the early history of web-based comics, many of which have since been printed and bound in traditional published formats. This volume is an effective overview of a burgeoning (and evolving) industry.

Daniels, L. (1991). Marvel: Five fabulous decades of the world's greatest comics. New York, NY: Harry N. Abrams.

Comics historian Les Daniels follows the history of Marvel Comics, one of the two largest comic book publishers in the world. The book actually begins with the earliest history of comic books and contextualizes the development of the Marvel imprint. Throughout this chronological approach, Daniels offers a series of encyclopedic entries for important characters created by the publisher, providing "Super Hero Profiles" of famous figures. The final chapter includes reprints of some classic stories from the first half-century of Marvel.

Daniels, L. (1995). DC comics: Sixty years of the world's favorite comic book heroes. Boston, MA: Bulfinch Press.

In a pseudo-companion volume to his book on Marvel, Les Daniels traces the history of DC Comics. Like the other book, this history is a very image-heavy book, as befits a reference on an art-driven medium. It features a series of short entries arranged in chronological order and with strong resources about the movement of comic books (through adaptations for film, television, and radio, as well as through merchandise) into the mainstream pop cultural world. This volume includes information on international publications of DC Comics characters and books, but its chief focus (and interest for the reader) is on the prevalence of DC Comics throughout the United States.

Cowsill, A., Irvine, A., Manning, M., McAvennie, M., \& Wallace, D. (2010). DC comics: Year by year-a visual chronicle. New York, NY: DK Publishing.

Using a "year by year" approach, this pictorial reference traces publisher DC Comics from 1935 and its genesis through the twenty-first century. Each year has a capsule overview before months and important publications are highlighted within each section. The selections of titles to represent key points for each year allows for otherwise forgotten issues to be illustrated for readers. Obviously, this focuses on the one publisher in its material, and that 
telescopic approach may be its one limitation, as entries do not necessarily reflect broader publishing issues of the times or possible reactions DC Comics had to its competitors to drive some of the trends exhibited.

Hofius, J., and Khoury, G. (2010). Age of TV heroes. Raleigh, NC: TwoMorrows Publishing.

Hofius and Khoury's volume is an impressive review of the televised adventures of comic book characters. After starting with a detailed "Comic Book-to-TV Hero Timeline," the reference breaks into sections based on the comic characters being adapted, with each chapter giving an overview and details about the productions which have brought these comic book figures to television. The book is concerned with live-action productions, and it impressively relates the stories behind the scenes, with background information on the transformation of comic books into a new medium. Three special sections ("Commercial Breaks") are interspersed in the book, detailing children's TV hosts who donned superhero personas, the 1980s comic-book inspired series The Greatest American Hero, and a 1970s live-action water show, "A Salute to the Super Heroes." These interludes reveal the far-reaching influence of comic books, while the entire book is a visual and textual wealth of information about the legacy of the super-hero through television and beyond.

\section{McCloud, S. (1993). Understanding comics: The invisible} art. New York, NY: HarperCollins.

Readers seeking a greater understanding of techniques and styles used to produce comic books should read McCloud's book. This book about the ways to create graphic novels is a graphic novel itself, with all of the information presented in a sequential art form, with a character representing the author narrating to the reader (through panels and word balloons) just what he or she is reading and explaining how the art of comics is produced (and how that art produces its narrative effects). Along with its short history of the medium and explanation of artistic practices, the book features a vocabulary for comics.

Hofstede, D. (1991). Hollywood and the comics: Film adaptations of comic books \& strips. Las Vegas, NV: Zanne-3. Though it is clearly dated today, this reference volume is the earliest published resource on comic adaptations for film and television, and, as such, it is a noteworthy effort to collect information on many productions. Arranged in alphabetical order, the volume provides overviews of more than fifty theatrical films and made-for-television movies. Each entry includes a cast list, a synopsis of the movie, a short review essay with a rating (based on a four-star system), and brief filmographic information (year of release, director, screenwriter, producer, studio, running time, and credits for the film's music, along with the now clearly-dated information on whether or not the production is available on videocassette). The final chapter (titled "And There's More...") details a variety of films which were not, at that time, available for home video, in a quick series listing movie serials, film shorts, (failed) TV pilots, and a few television series not discussed elsewhere.

Burke, L. (2008). The Pocket essential superhero movies. London, England: Oldcastle Books.

As its name implies, this book is a short ready reference volume about films based on comic books and superhero characters. The book is broken into chapters that separate the films by type, but it also is an effective source which gives detailed synopses of these films with overviews of the source material and trivia about each production. Although it is a fairly recent book, it is limited in that a significant number of blockbuster films based on comic books have come since this book's publication, and it could certainly stand an updated edition.

Overstreet, R. M. (2014). The Overstreet comic book price guide \#44. New York, NY: Gemstone Publishing.

The Overstreet Comic Book Price Guide is an annual publication which began with a singular purpose (to catalog current prices for issues of comic books, thus serving as a price reference for collectors). However, over the years it quickly evolved into a more thorough publication with a broader purpose. Each year, the guide is published with updated pricing information, but it also includes essays about comics history, galleries of covers, publication information on comics dating from the beginning of the medium's history (and even including data about books which were published before the recognition or naming of the genre, with facts about "proto-comic books" from early eras), and trivia related to individual issues of comics (such as notes about the appearances, in cameos and larger roles, of specific characters, or the first work by a writer or artist on a book, and even offering notes about guest artists or even ghost work by writers and artists who went un-credited at the time of publication but are now known to have worked on that issue). The latest volume of Overstreet (with Robert Overstreet's work prevalent enough that his name now functions, like Roget's, to identify his reference volume) includes, along 
with the data and prices by issue of comic titles, essays on the $75^{\text {th }}$ Anniversary of Batman and a history and overview of rare Canadian comics. For many collectors, given the volatile nature of the comic "back issue" market, this text serves more effectively as a reference for publication information and other similar facts than an absolute pricing guide (particularly with the more-immediate options available to check on the internet for online auctions and sales), though both aspects make it an important almanac of comic book information.

Schoell, W. (1991). Comic book heroes of the screen. New York, NY: Citadel Press.

An erudite overview of film and television adaptations of comic books, Schoell's history is an engaging reference which reveals both comic publication history and the popular culture effects of recreating comics on the screen (both silver and small). The chapters are organized around characters, with chronological approaches within each chapter. Four sections are devoted to single (and significant) figures in comics/comic book adaptation history: Superman, Batman, Captain America, and Captain Marvel. (Within these chapters, related productions and spinoffs are also presented and discussed.) The remaining sections then cover "Other Heroes" (those characters who, at the time of this book's early publication, had only had a few productions based on their comic books; in an updated edition, these characters would most likely have separate chapters devoted to their different adaptations), "Super-Heroic TV Shows" (revealing the influence of comic books through series which are clearly inspired by super-heroic stories), "Comic Book Cliff-Hangers" (the comic book-based and inspired serials from the 1930s $\&$ 1940s), and "Bring on the Heroes" (revealing the continued influence of comic books by detailing more recent films inspired by comic books). The book ends with a brief filmography and a brief "select bibliography" of further sources on the topic.

\section{Biographies}

Horn, M. (Ed.). (1986). Contemporary graphic artists: A biographical, bibliographical, and critical guide to current illustrators, animators, cartoonists, designers, and other graphic artists. Detroit, MI: Gale.

This three-volume reference set provides alphabetic entries on those responsible for the illustrative components of comic books and graphic novels. Each entry includes personal biographical information (including education/ training for the artists and studios, as applicable), career information, any exhibitions for the artists' respective work, awards \& honors won, a short list of biographical and critical sources for each artist, and "Sidelights," a section of further information about the artist, including trivia, as well as work the artist might have done (such as for posters or other advertisements) which is not as readily available. The first volume contains an overview of the graphic arts, wherein Horn offers a history of illustration. Perhaps the most intriguing feature of this series is that each volume contains entries for artists, A-Z, with different artists discussed in each (i.e. the first volume does not cover from $\mathrm{A}-\mathrm{H}$, then the second I-P, then the third Q-Z; instead, each volume has sections for each letter of the alphabet, with the alphabetized listing starting over each time). There is a cumulative index, telling which artist is found in which volume. The effect is that each volume can feel self-contained, but it also points to the ever-growing field of graphic art, as it shows the potential continually to expand lists of significant contributors to comics.

Comiclopedia - Illustrated Artist Compendium. (2015). Retrieved from https://www.lambiek.net/comiclopedia.html This site provides biographical information on over 12,000 comic book artists and writers and is updated daily with new entries and updates to existing entries. In addition to biographical information on each artist, entries also include notable samples of artwork for each artist. Anybody interested in the artistic and creative side of comic books, and not simply the creations themselves, will find a wealth of useful information on this site.

\section{Geographical}

Atlas of the DC universe. (2015). Retrieved from

http://www.karridian.net/dcatlas.html

Combining information from the (long out-of-print) Atlas of the DC Universe (a supplement for a role-playing game based on DC Comics, published in 1990) and the comic book Secret Files: Guide to the DC Universe (an almanac-style comic offering reference information on fictional places, organizations, and characters from DC Comics, published in 2000), this geographic source provides information on the settings found in this publisher's works. The website has also updated its information as individual comic stories have offered further information on the locales for adventures. The site offers interactive maps of the world and the United States, and users can click on highlighted areas (or on regions of the US) for hyperlinks to entries about the places. This atlas is about the fictional countries and cities that have appeared in DC Comics, but the entries do connect these 
places to real-world analogues and near-by actual places. A nearby note at the bottom of the webpage asks readers to submit updates as they find them and acknowledges the challenge of being comprehensive, given the constant output of new issues of comic books. The difficulty in staying up-to-date is the main limitation for a reference of this type, though having a website (which can be updated fairly easily) allows easy updating, as needed and as available.

Hilgart, J. (2015). Comic book cartography. Retrieved from http://comicbookcartography.posthaven.com/

This site is no longer regularly updated, but it does contain official maps, blueprints, and schematics of lands, buildings, and technological items from both Marvel and DC. Anybody interested in the maps of the comic world would benefit from seeing some of the items posted on this website.

The secret geography of the DC universe: A really big map. (2011). Retrieved from http://ifanboy.com/articles/ the-secret-geography-of-the-dc-universe-a-really-big-map/ Offering a scanned map from the 1990 out-of-print Atlas of the DC Universe (a supplement for the DC Comics role-playing game, a spinoff from the comics), this website provides a geographic reference for the locations found in comic books from that publisher. The map can be zoomed in on with a click, but that is the limitation on any interactive features. However, it does provide scans of the full United States map and a sample of the map of the New England region. As this website simply reprints the map from the role-playing resource, it is more an historic map of a comics world than a current one, but it does provide a nice introduction to the geographic possibilities for this publisher.

\section{Government Documents}

Comic Book Legal Defense Fund. (2015). Retrieved from http://cbldf.org/

This website contains the history and text of all iterations of the Comics Code Authority, the internally governing document that dictated what could and could not be included in any widely distributed comic book. It also contains case files for notable obscenity cases and several other legal documents relating to free speech, obscenity, and comic books. Anybody interested in the legal history of comic books and censorship will find a bevy of information on the topic here.

\section{Documentary Sources}

Devine, S. \& Kenny, J.M. (Producers \& Directors). (2013). Necessary evil: Super-villains of DC comics. [Documentary]. Los Angeles, CA: Warner Home Video.

Narrated by Christopher Lee, this documentary examines the rich history of super-villains within the books produced by DC Comics. The film provides background and analysis on several key antagonists, with an emphasis on more recent appearances and characters. The documentary acknowledges the changing perceptions of many of these characters over the years.

Kantor, M. \& Rosenthal, S. (Producers), \& Kantor, M. (Director). (2013). Superheroes: A never-ending battle. [Documentary]. Washington, DC: PBS Direct.

This three-part documentary series traces the evolution of superhero characters and the comic book industry, with an overview of the change in perception of comics as a kid-based milieu into one enjoyed by readers of all ages (and as one which now produces multi-million dollar revenue. The series includes interviews with comics historians, industry insiders, including many writers and artists, and with personalities and actors associated with superheroes and comics and their related adaptations.

Welch, S, \& Eckholm, J. (Producer), \& Carter, M. (Director). (2010). Secret origin: The story of DC comics. [Documentary]. Los Angeles, CA: Warner Home Video.

A documentary detailing the history of DC Comics, this film provides a compelling overview of the publisher's history, with interviews with writers and artists from the company and insight from comics historians. The history touches on the origins of the medium and on some of DC Comics' competitors, but its primary strengths come in the presentations of images and illustrations from throughout the DC Archive. Narrated by Ryan Reynolds (who in that year starred in the DC Comics-based film Green Lantern), the documentary does provide a sort of advertisement for more recent adaptations, but it also offers views of a variety of aspects of DC Comics and its legacy.

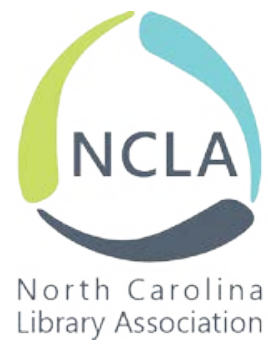

